\title{
Submucosal tunneling endoscopic septum division for Zenker's diverticulum: a re- producible procedure for endoscopists who perform peroral endoscopic myotomy
}

Zenker's diverticulum is a rare disease occurring in less than $0.5 \%$ of the global population. Currently, the diverticuloscope-assisted diverticulotomy represents the traditional procedure, the diverticuloscope enabling better exposure of the muscular fibers. Although effective and safer than surgery, this technique could be complicated by perforation, which is reported in as many as 6.5 $\%$ of patients [1]. Recently, Li et al. reported a novel technique called the submucosal tunneling endoscopic septum division (STESD) [2], inspired by the peroral endoscopic myotomy (POEM) technique [3]. The theoretical advantage is to completely dissect the muscular septum without mucosal opening. This video case reports the second successful treatment of Zenker's diverticulum using this new procedure.

A 72-year-old woman underwent upper endoscopy for dysphagia, revealing a Zenker's diverticulum $20 \mathrm{~cm}$ from the incisors ( $\triangleright$ Fig. 1 ), which was confirmed by esophagogram ( $>$ Fig.2). We performed the diverticulotomy using the STESD technique ( $\triangleright$ Video $\mathbf{1}$ ) and a gastroscope (Fujinon, Tokyo, Japan) with cap.

Submucosal incision was performed after submucosal injection, $3 \mathrm{~cm}$ above the diverticular septum. A tunnel was made using a $1.5 \mathrm{~mm}$ FlushKnife (Erbe Elektromedizin, Tübingen, Germany) between the muscular layers and the mucosa until the muscular septum was reached, and then continued along both sides of the septum, to create a large endoscopic window. Thereafter, the diverticular septum was completely dissected (with spread coagulation) along its entire length. Finally, after hemostasis, the mucosal incision was closed by four clips.

Intravenous antibiotics were continued for 2 days postoperatively, and the patient was discharged at Day 3. Symptoms had totally resolved 15 days later.

In summary, STESD is a reproducible technique that is easily accessible to en-

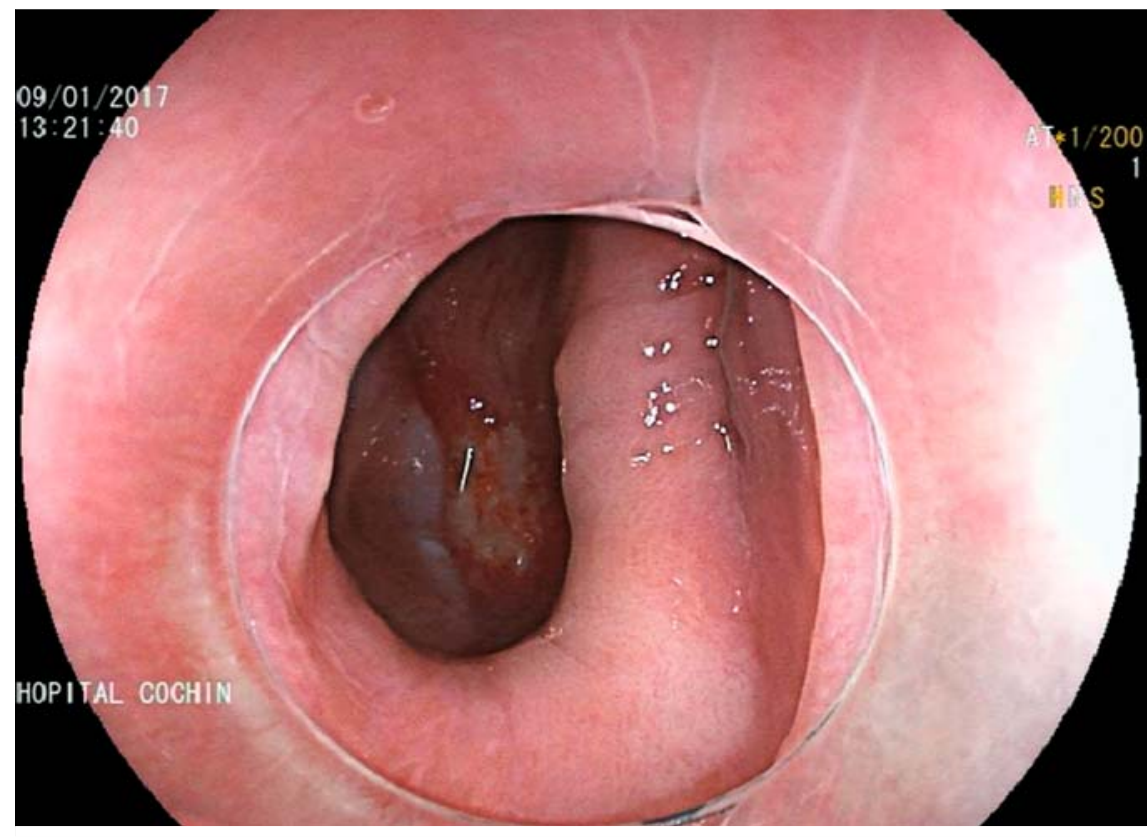

- Fig. 1 Endoscopic view of the Zenker's diverticulum with a cap-assisted gastroscope (Fujinon, Tokyo, Japan).
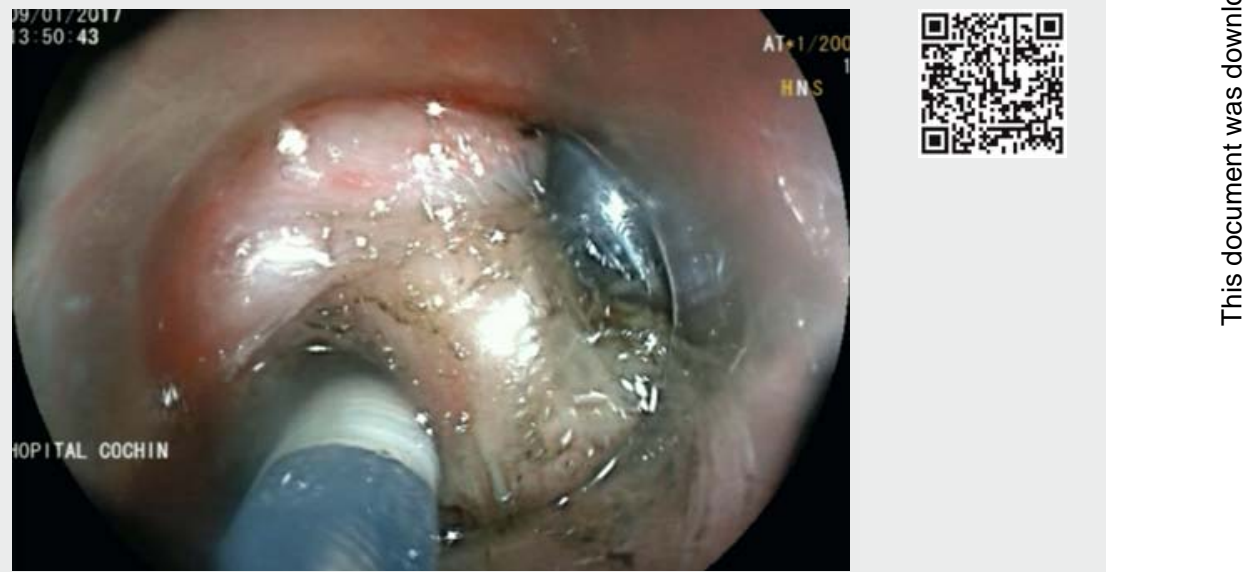

Video 1 Submucosal tunneling endoscopic septum division for Zenker's diverticulum: Zenker's examination; submucosal injection; incision with submucosal tunneling; dissection of the muscular septum; closing with clips. 


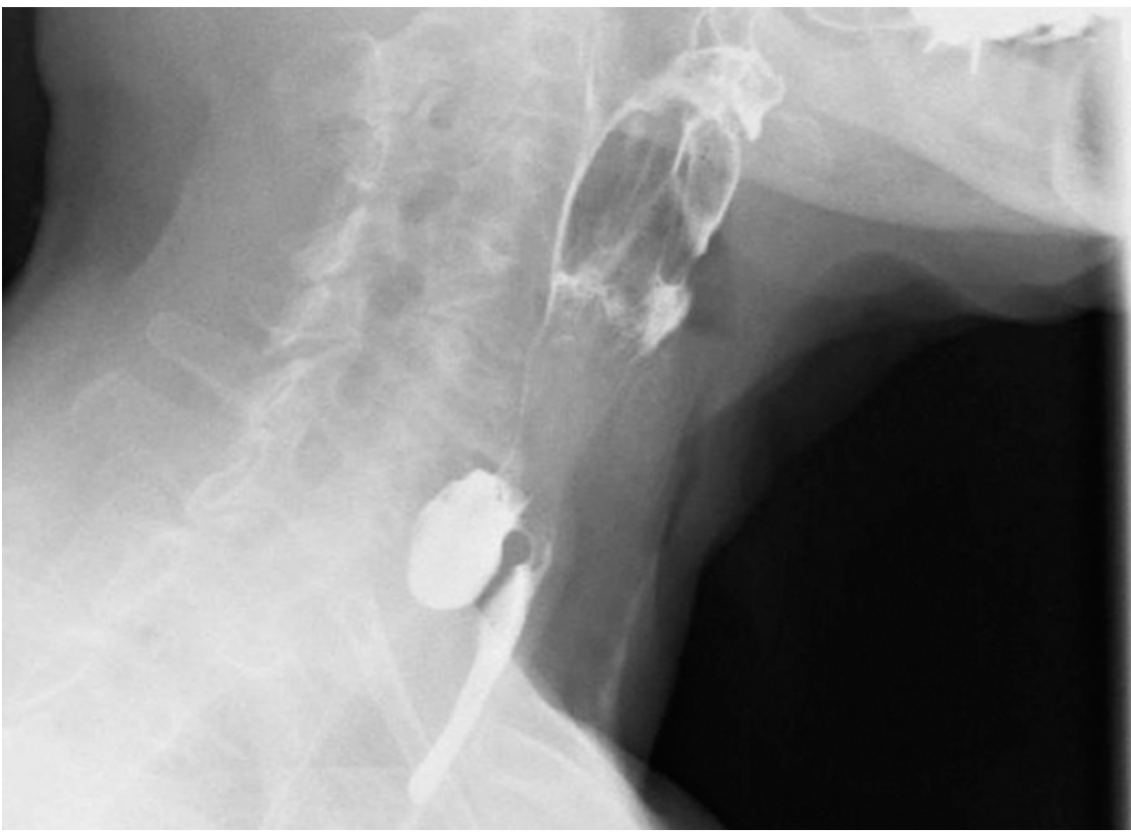

- Fig. 2 Zenker's diverticulum in an esophagogram in sagittal plan.

doscopists who have experience of the POEM procedure. Further studies are required to validate this technique and compare it with classic diverticuloscopeassisted diverticulotomy.

Endoscopy_UCTN_Code_TTT_1AO_2AG

Competing interests

None
The Authors

Bertrand Brieau' ${ }^{1}$, Sarah Leblanc ${ }^{1}$, Benoit Bordacahar $^{1}$, Maximillien Barret ${ }^{1,2}$, Romain Coriat ${ }^{1,2}$, Frederic Prat ${ }^{1,2}$, Stanislas Chaussade $^{1}$

1 Service de gastro-entérologie et oncologie digestive, Hôpital Cochin, Université Paris Descartes, Paris, France

2 Unité INSERM U1016, Paris, France

Corresponding author

\section{Bertrand Brieau, MD}

Service de gastro-entérologie et oncologie digestive, Hôpital Cochin, 27 rue du Faubourg Saint Jacques, 75014 Paris, France Fax: +33-1-58411952

bertrand.brieau@aphp.fr

\section{References}

[1] Ishaq S, Hassan C, Antonello A et al. Flexible endoscopic treatment for Zenker's diverticulum: a systematic review and meta-analysis. Gastrointest Endosc 2016; 83: 1076 1089.e5

[2] Quan-Lin L, Wei-Feng C, Xiao-Cen Z et al. Submucosal tunneling endoscopic septum division: a novel technique for treating Zenker's diverticulum. Gastroenterology 2016; 151: $1071-1074$

[3] Inoue H, Minami H, Kobayashi Y et al. Peroral endoscopic myotomy (POEM) for esophageal achalasia. Endoscopy 2010; 42: 265 271

\section{Bibliography}

DOI https://doi.org/10.1055/s-0043-105574

Endoscopy 2017; 49: 613-614

(c) Georg Thieme Verlag KG

Stuttgart · New York

ISSN 0013-726X

\section{ENDOSCOPY E-VIDEOS}

https://eref.thieme.de/e-videos

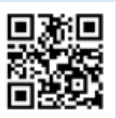
Endoscopy E-Videos is a free access online section, reporting on interesting cases and new techniques in gastroenterological endoscopy. All papers include a high quality video and all contributions are freely accessible online.

This section has its own submission website at

https://mc.manuscriptcentral.com/e-videos 